\section{Dr. Wolfe replies}

\section{To the Editor:}

This is the fifth letter to me from Dr. Toda in the form of a letter to the editor since the publication of the 2010 criteria. Here is another answer. By either the American College of Rheumatology 2010 or the modified criteria of 2011 , the only way to satisfy fibromyalgia (FM) criteria is by meeting 1 of the following conditions: widespread pain (WPI) $\geq 7$ and symptom severity scale (SSS) $\geq 5$ or WPI $3-6$ and SSS $\geq 9^{1,2}$. If one adds together the WPI and SSS, the result is the polysymptomatic distress (PSD) score or, as the scale has also been called, the FM symptom (FS) scale or score. Dr. Toda is correct that the PSD is "useful to evaluate FM severity." Because the probability of meeting the FM criteria increases with increasing PSD score, the PSD can serve as an approximate measure of FM diagnosis. In my review of the literature, the FS scale misclassifies $4 \%$ to $8 \%$ of cases when compared [(WPI $\geq 7$ and SSS $\geq 5$ ) or (WPI 3-6 and SSS $\geq 9$ )], so that it is probably not a good idea to use cutpoints for diagnosis in the individual patient.

I believe that Dr. Toda is confused when he speaks of a "change of cutpoint from 13 to 12." We did not change cutpoints. The PSD cutpoint is the cutpoint that leads to the least misclassification of cases and non-cases when many patients are studied, and it can vary from study to study. So, in some studies that might be 12 and in others 13 , and still others yet a different number. The cutpoint is not a number that I or some criteria determine. It is determined by the distribution of scores and cases in the study sample. For example, suppose there are 200 cases: 100 non-cases with PSD scores between 0 and 11, and 100 cases with PSD scores between 12 and 31. In that case, the cutpoint will be 12 and there will be no misclassification. However, in another sample there are 100 non-cases with PSD scores between 0 and 11, and 50 non-cases with PSD scores between 12 and 15, and 50 cases with PSD scores between 16 and 31. It is clear that a cutpoint of 12 would misclassify 50 cases, but a cutpoint of 16 would misclassify no cases.
As to what is the clinical value of a difference in the PSD score of 1 unit, I refer Dr. Toda to an article in The Journal that gives insight into differences in PSD scores (and also Figure 1 of that article, a good example of standard criteria vs PSD cutpoint as criteria) ${ }^{3}$. Ultimately, the importance of differences is a decision for clinicians.

There is not enough space to reply to your question about the meaning of FM. But we have done this elsewhere and we recommend that article to you ${ }^{4}$.

FREDERICK WOLFE, MD, National Data Bank for Rheumatic Diseases, and University of Kansas School of Medicine, Wichita, Kansas, USA. Address correspondence to Dr. F. Wolfe, National Data Bank for Rheumatic Diseases, 1035 N. Emporia, Ste. 230, Wichita, Kansas 67214, USA.E-mail: fwolfe@arthritis-research.org

\section{REFERENCES}

1. Wolfe F, Clauw DJ, Fitzcharles MA, Goldenberg DL, Katz RS, Mease P, et al. The American College of Rheumatology preliminary diagnostic criteria for fibromyalgia and measurement of symptom severity. Arthritis Care Res 2010;62:600-10.

2. Wolfe F, Clauw D, Fitzcharles MA, Goldenberg D, Häuser W, Katz RS, et al. Fibromyalgia criteria and severity scales for clinical and epidemiological studies: a modification of the ACR Preliminary Diagnostic Criteria for Fibromyalgia. J Rheumatol 2011;38:1113-22.

3. Wolfe F, Walitt BT, Rasker JJ, Katz RS, Häuser W. The use of polysymptomatic distress categories in the evaluation of fibromyalgia (FM) and FM severity. J Rheumatol 2015; 42:1494-501.

4, Wolfe F. Editorial: the status of fibromyalgia criteria. Arthritis Rheumatol 2015;67:330-3.

J Rheumatol 2016;43:2; doi:10.3899/jrheum.151128 